\title{
1 Causal Understanding of the Stone Dropping Task in Two
}

\section{Species of Macaw}

3 Laurie O'Neill $^{1,2}$, Anthony Picaud, Ronan Hastings, Nina Buffenoir, Manfred Gahr ${ }^{1}$, Auguste M.P. von

4 Bayern ${ }^{1,2,3}$

$5 \quad{ }^{1}$ Max Planck Institute for Ornithology, 82319, Seewiesen, Germany

$6{ }^{2}$ Max Planck Comparative Cognition Research Station, Loro Parque Fundacion, 38400, Puerto de la Cruz,

$7 \quad$ Tenerife, Spain

$8 \quad{ }^{3}$ Department Biology II, Ludwig-Maximilians-University of Munich, Martinsried, Germany 


\section{Abstract}

Causal understanding in animal cognition can be divided into two broad categories

(Woodward, 2011): learned associations between cause and effect (Le Pelley et al., 2017) and understanding based on underlying mechanisms (Johnson and Ahn, 2017). One experiment that gives insight to animals' use of causal mechanisms is the stone-dropping task. In this, subjects are given an opportunity to push a platform to make it collapse and are then required to innovate dropping a stone tool to recreate the platform collapsing (von Bayern et al., 2009). We describe how $16 / 18$ subjects of two species of macaw $(n=18 ; \operatorname{Ara}$ ambiguus $(n=9)$ \& $\operatorname{Ara}$ glaucogularis $(n=9))$ were able to innovate the solution in this task. Many of the subjects were able to innovate the behaviour through exploratory object combination, but it is also possible that a mechanistic understanding of the necessity for contact with the platform influenced some subjects' behaviour. All the successful subjects were able to recreate their novel stonedropping behaviour in the first or second trial after innovation (and all trials thereafter) and they were also able to do the behaviour increasingly faster. This suggests they also rely on learned associations of cause and effect. However, in a transfer task in which subjects had to

27 guide a stick tool to make it touch a differently positioned platform, all but one of the subjects 


\section{Introduction}

outgoing behaviour. Causal cognition is specifically the individual's understanding of the cause and effect relationships they observe in their environment. Some have suggested that causal reasoning skills are a key tenet of complex cognition (Emery and Clayton, 2004) and thus are likely to be present in multiple species that have evolutionary pressures for 'intelligent' behaviour (Van Horik et al., 2012). It could be that it is one of the cognitively complex processes that make some species more behaviourally flexible, innovative and thus successful at rapidly adapting to new environments (Lefebvre et al., 1997; Sol et al., 2007, 2005, 2002). By studying how different species mentally represent causal relationships we can learn more about the evolution of causal understanding and its role in the evolution of complex cognition. Causal relationships are probably grasped through more than one cognitive process. As an example, think of a crow that opens a snail shell by dropping it onto a concrete path running through its territory. Does the crow only recognize the spatial connection between the successful opening of shells and the concrete area or do they specifically recognize that the concreted area is made of a harder material, and that hard materials break things more easily.

Within this example is the description of two forms of causal understanding. The former form of understanding is an associatively learnt account of a causal link between events that are spatially or temporally connected (Hanus, 2016; Le Pelley et al., 2017) and has been referred to as 'difference making' understanding (Woodward, 2011). The latter form of understanding specifies the underlying causal mechanism, for example the physical forces that link a cause to

its effect (Johnson and Ahn, 2017) and has been referred to as 'geometrical-mechanical' 
understanding (Woodward, 2011). Studies investigating a species' causal cognition do not often recognized under different names. For example, geometric-causal bears similarities to 'folk-physics' (Povinelli, 2000) whereas difference-making understanding is regularly dismissed as not being causal understanding due to its associatively-learnt properties. Although difference-making understanding requires learning, a learned causal link is still a form of causal cognition (Hanus, 2016; Le Pelley et al., 2017) and flexible physical problem solving skills (Lambert et al., 2018). They also one of the groups of animals that have both relatively large, neuronally dense brains (Gutiérrez-lbáñez et al., 2018; Herculano-Houzel, 2017; Iwaniuk et al., 2005; Olkowicz et al., 2016) and known environmental stochasticity (Toft et al., 2016) that suggest they may use complex causal cognition processes in their daily life (Osvath et al., 2014; Van Horik et al., 2012). A notable example of their technical competence is their ability to use tools in captivity. In the wild, there

67 are just a few examples of parrots using tools (Goodman et al., 2018; Heinsohn et al., 2017;

Osuna-Mascaró and Auersperg, 2018; Villegas-Retana and Araya-H., 2017; Wood, 1984), but in captivity two species, kea (Nestor notabalis) and Goffin's cockatoos (Cacatua goffiniana), have been shown to innovate stick tool use in problem-solving situations (Auersperg et al., 2011; Auersperg et al., 2012). The tool use innovation reported from Goffin's cockatoos was particularly remarkable as one individual even innovated the manufacture of a tool. This kind

73 of flexible tool-use from a non-habitually tool using animal suggests the species exhibits elements of complex physical understanding of object properties (Bird and Emery, 2009; 
75 Kacelnik, 2009). It is thus important to test the causal understanding and cognitive abilities of

76

77 more parrot species on physical causal understanding tasks to learn about its role in all of parrots' cognitive evolution.

The species tested here belong to the genus Ara (the macaws) in the parrot superfamily Psittacoidea. They are relatively distantly related to the Kea (superfamily Strigopoidea) and the Goffin's cockatoos (superfamily Cacatuoidea) with a last common ancestor approximately 50mya (Kumar et al., 2017; Wright et al., 2008). We tested two species of macaws: Ara glaucogularis and Ara ambiguus. These macaws had previously completed a range of causal understanding tasks as part of a larger cognitive test battery (Krasheninnikova et al., 2019) and also completed a modified trap-tube task (O'Neill et al., 2018). Both of these experiments were object choice tasks with two or three options to choose from and it turned out the subjects developed some rules of thumb (heuristics), such as side biases or random choice, that allowed subjects to attain a satisfactory amount of rewards without any 'cognitive effort'. To avoid this, we decided to design an experiment that did not include choice elements but instead presented the subjects with a novel problem-solving task.

We gave the subjects the stone-dropping task (Bird and Emery, 2009; von Bayern et al., 2009). In this task, a subject was first able to push a collapsible platform with their beak to release a food reward. The platform was then placed out of reach to see if the subject could recreate the effect of the platform pushing behaviour by innovating a novel causal input: dropping a stone onto it. Two out of four New Caledonian Crows (Corvus moneduloides) were able to recreate this force by dropping a stone tool onto the platform (von Bayern et al., 2009). It is not clear exactly what kind of understanding these crows used to solve the task. They may 
97 have understood that they were required to make contact with the platform and had

98

99

100

101

102

103

104

105

106

107

recognised that dropping a stone was an alternative form of contact. The understanding that contact was the key factor would suggest that the crows had an understanding based on the mechanism underlying the function of the apparatus. However, it appears unlikely that they understood more complex mechanical properties of the task such as the importance of the stone's weight, as other New Caledonian crows did not initially discriminate between dropping heavy and light stones in a follow up task from a replication study (Neilands et al., 2016). However in this replication, only a single New Caledonian crow of twelve was able to innovate the stone-dropping behaviour. Further, it was interesting to note that these subjects were also able to learn that only heavy stones were functional in making the platform collapse (Neilands et al., 2016).

It seems unlikely that the birds' initial stone-dropping actions were down to a learned, difference-making, causal understanding, as they had never observed the effects of a stone being dropped onto the platform before. However, many subjects began to drop more stones into the apparatus after the platform had collapsed, suggesting that they had also formed a difference-making understanding that the dropping of stones led to the appearance of the reward (Neilands et al., 2016). It was unlikely that the behaviour was driven by spontaneous exploration as the birds were given extensive opportunity to explore the apparatus in the presence of stones, before they were given the opportunity to push the platform with their beak, and they never dropped a stone in at this point (von Bayern et al., 2009).

The rationale of the current experiment was thus as follows. Subjects are given an opportunity to solve the task without any experience of how the platform in the apparatus can 
move. This phase is called the pre-test. If subjects are able to solve the experiment at this stage (see supplementary video 1 for an example of a successful solution) then it suggests they are capable of solving the task through exploratory behaviour alone. This is because they cannot be using a causal understanding of how an apparatus works if they have never had experience of any of its functional properties before.

They were then given an opportunity to experience the collapsibility of the platform and resulting release of food by being allowed to collapse it themselves directly by pushing it (see supplementary video 2). This platform pushing experience gives the subjects knowledge of the functional mechanism underlying the required action of the task, but not the direct actions they need to take to solve the task by dropping stones. Following this, another test phase is given (critical test phase), which is identical to the pre-test phase except it was now possible to see if and how experience of the functional mechanisms had changed their behaviour. If they immediately began to drop rocks on the platform at this stage, it suggested the subjects had developed an understanding of the causal mechanism of the platform, i.e. that it can be collapsed by exerting force or making contact with it, and were trying to activate this mechanism in another way.

After this, it is vital to then see if subjects continue to persist with the stone-dropping behaviour. This is to ensure that they have not done it accidentally. It is also possible to then see the extent to which the subjects recognised the effects of their own behaviour from the first stone drop onwards. If they begin to drop stones with a reduced latency after the first successful stone drop, it suggests an egocentric understanding of the effects they have caused on the apparatus. Thus they can learn quickly to repeat the successful behaviour. 
If the subjects were successful in dropping stones onto the platform, we also planned a

142 transfer task to specifically observe whether they recognised the importance of contact

143 between an object and the platform to make it collapse. This transfer task involved partially

144 moving the platform from directly underneath the tube into which they could drop stones in,

145 this meant objects dropped into the tube would not automatically make contact with the

146 platform. Instead subjects would have to use a stick tool inserted at an angle to make contact

147 with the platform. Thus subjects that only had a learned causal understanding that objects

148 dropped into the apparatus made rewards appear would struggle to complete this transfer

149 task. Success in this transfer task would add more confirmatory evidence that subjects

150 recognised the mechanism that made the apparatus function.

We expected that at least some individuals of the two macaw species tested would be

152 able to drop stones. They have shown previous success in another test for causal

153 understanding (O'Neill et al., 2018) and they are known to be highly exploratory and keen at

154 handling objects, so were likely to interact with the stones given to them. We were unsure if

155 the macaws would do this immediately after the experience phase given to them, as they have

156 not previously shown mechanistic causal understanding in previous experiments. 


\section{Methods.}

\section{Subjects and housing}

Nine A.ambiguus and nine A.glaucogularis were tested. Their age and sex are shown in

Table 1. All the birds were hand-raised and group reared by the Loro Parque Foundation in

Tenerife, Spain, and all were housed in the Comparative Cognition Research Station, within the

162 Loro Parque zoo in Puerto de la Cruz, Tenerife. The birds were housed in groups of 2-8

163 individuals, according to species and age, in seven aviaries. Six of these aviaries were $1.8 \times 6 \times 3$

164 metres (width $\mathrm{x}$ length $\mathrm{x}$ height) and one was $2 \times 6 \times 3$ metres. Windows of $1 \times 1 \mathrm{~m}$ could be opened between the aviaries to connect them together. One half of the aviaries was outside, so the birds followed the natural heat and light schedule of Tenerife. The half inside the

167 research station and was lit with Arcadia Zoo Bars (Arcadia 54W freshwater Pro and Arcadia 54W D3 Reptile Lamp) that followed the natural light schedule. again in the afternoon. In the afternoon, each individual received a portion of Versele Laga Ara

171 seed-mix that was modified based on their daily weight. The parrots were never starved,

172 controlled portions of seeds were fed to prevent overeating and obesity. Testing took place at

173 least an hour after the parrots had breakfast to ensure there was sufficient motivation to get

174 food rewards. Unless otherwise specified, walnut halves were used as rewards. These were

175 highly prized by all subjects, and they were able to obtain them on a daily basis through

176 voluntary testing. 
178

179

180

181

182

183

184

185

186

187

188

189

190

191

192

193

194

195

196

197

\section{Experimental rooms}

Experiments took place in separate testing rooms away from the aviaries. All birds had been previously trained to enter in them. These rooms were $1.5 \times 1.5 \times 1.5 \mathrm{~m}$ and also lit with Arcadia Zoo Bars to cover the birds' full visual range. One wall of each one of the experimental rooms had a $50 \times 25 \mathrm{~cm}$ window through which an experimenter could place apparatuses into the testing room from a neighbouring chamber. This window could be occluded with a white board so that the experimenter could hide anything they were doing from the subjects' view, such as re-setting apparatuses between trials. The experimenter always wore mirrored sunglasses during experiments to prevent their gaze being a cue for the parrots. A second wall was made of sound proofed one-way glass so that zoo visitors could observe experiments without disturbing the subjects.

\section{$\underline{\text { Apparatus }}$}

The apparatus had a hinged platform held up by two $8 \times 8 \mathrm{~mm}$ neodymium disc magnets (www.supermagnete.de, $2.5 \mathrm{~kg}$ strength) that magnetised to two screws. A transparent acrylic shell $(25 \times 20 \times 10.5 \mathrm{~cm})$, marked with blue stripes to show the solidity of the acrylic, enclosed the platform. A reward was placed on top of this platform and was inaccessible unless the magnets released the hinged platform into a sloped position, allowing the reward to roll out from another hole at the bottom of the apparatus (Figure 1). For the pre-test and critical test, the only access hole to the platform was via a small rectangular tube, placed on top of the shell. The platform was $10 \mathrm{~cm}$ below the top of this tube, which meant the parrots could not reach in and touch the platform. The opening at the top of the tube was a rectangle of $7 \times 4.5 \mathrm{~cm}$, 
which was also small enough to prevent the birds from placing their heads directly inside the hole. The entire apparatus was mounted on a solid wooden board ( $45 \times 30 \times 2.5 \mathrm{~cm}$ ).

A slightly modified version of the apparatus was used for the platform-pushing phase. A different transparent acrylic shell was placed on the apparatus that allowed the subjects to access the platform. In place of the tube, this shell had an opening so that the birds could push the platform directly with their beaks (Figure 1, A \& B). However, this structure still blocked the parrots' direct access to the reward that was resting on top of the platform.

The stone tools provided in the pre-test and critical tests were natural volcanic rocks taken from the beach in Puerto de la Cruz, Tenerife. They were returned to the beach after testing was finished. They had a diameter of $4.5-5.5 \mathrm{~cm}$ and weighed between $60-100 \mathrm{~g}$. It was ensured they were all sufficiently heavy to break the connection between the magnets holding up the platform when dropped from a height of $5 \mathrm{~cm}$, i.e. half the height of the tube.

\section{Experimental procedures}

Within these descriptions, a 'session' is a single period of time in which a subject was taken to a testing room, a 'trial' is a single opportunity to interact with the test apparatus and obtain a reward. Thus multiple trials could take place within a single session. A single trial could last for a maximum of ten minutes; if a subject had not succeeded within ten minutes then the trial and the session ended. If a subject succeeded within ten minutes, then the apparatus was rebaited and subjects were given another trial. There was a maximum of six trials in a session. Hypothetically sessions had a maximum time of thirty minutes, so as not to over-test the subjects, but this time limit was never reached. Typically subjects only had one 
session of testing per day. All subjects individually took less than a month to complete the whole experiment, from habituation to final critical test. The one exception was Hannibal, who took two months. Testing of the birds began in May 2017 and finished in January 2018.

$\underline{\text { Habituation }}$

were not scared of either of these and thus, to exclude neophobia as a confounding factor.

Although parrots are typically quite neophilic (Auersperg et al., 2015; Mettke-Hofmann et al., 2002), so are unlikely to have a neophobic response to novel apparatus and objects, there is variation between individuals. Specifically, older parrots may be more likely to show neophobic responses (O'Hara et al., 2017). As the subjects were of different ages (see Table 1), it was important to ensure that all subjects were equally comfortable with the apparatus.

sessions took place in the experimental rooms, with an experimenter sitting in the neighbouring chamber. Once the subject was in the experimental room, the experimenter introduced the apparatus through the window. Subjects had five minutes to approach the apparatus and take a piece of walnut placed at the base of the apparatus (where the reward would fall out in a successful trial). If they took it, the experimenter waited for 30 seconds then removed the apparatus. Next, the experimenter, out of sight of the subject, rebaited the apparatus and reintroduced it a minute after removing it. The subjects had up to six of these trials per session and if they took six walnut pieces in a row within a single session, they moved onto testing. 
In parallel, the subjects were habituated to the stone tools in their home aviaries. The

242 stones were placed inside the aviaries for the parrots to approach and explore as a group. Each

243 group of birds approached, picked up, and explored the tools extensively (although this was not

244 specifically measured). Additionally, each individual was also given an opportunity to explore

245 the tools whilst alone in an isolated area of the aviary. Each individual had held and interacted

246 with the stones more than once before they started testing.

The pre-test and critical test procedure were identical in both setup and procedure as

solution in the pre-test and after they had undergone the platform pushing experience phase

252 (see below), during which they had an opportunity to learn about the underlying mechanism of 253 the apparatus.

257 reasoning processes, but that their solution could by explained by more simple means, such as

258 a tendency to insert stones into cavities or to combine them with other objects regardless of

259 the causal outcome of this behaviour. On the contrary, if they did not drop stones in the pre-

260 test, but only began to do so in the critical test, this could be seen as an indication that having

261 experience of the underlying causal mechanism of the task (i.e. the collapsibility of the 
platform; see platform pushing experience below) caused a change in the subjects' behaviour, suggesting the subjects were capable of a more complex form of causal understanding based on mechanisms.

The protocol for the pre-test and critical test was as follows. Subjects were given six testing sessions once per day, with both the baited test apparatus and tools present. Each session had between one to six trials, depending on the subject's success, i.e. they were given more trials if they succeeded in a trial until the six trial limit for a session was reached. Initially, the whole apparatus was prepared out of sight in a neighbouring chamber to the subject's testing room, including baiting the apparatus with an attractive reward (half a walnut) and placing two stone tools on each side of the apparatus (four in total). The apparatus was then pushed into the subject's room through the window. The subject was allowed to interact with the apparatus for ten minutes. If they were not successful in this time, the trial (and the session) ended, the apparatus was removed and the subject was returned to its social group. If, however, a subject was successful in this time-span, and they were able to make the platform collapse through dropping stones into the tube, they would be given further trials immediately within the same session in order to examine whether they would continue to succeed in subsequent trials. The repetition of trials immediately after a successful stone drop was vital for verifying if the subjects could replicate their success and thus had grasped the causal outcome from their specific action, i.e. dropping the stone into the tube, or whether they had succeeded accidentally without recognising the difference-making properties of their behaviour. If they immediately repeated the behaviour after doing it once, it suggested that the behaviour was either originally purposeful, or that it was initially accidental but the birds at 
284 least had capable egocentric understanding of their behaviour. To implement a replication trial,

285 the experimenter waited 30 seconds after the subject had made the platform collapse and then

286 removed the apparatus. They would re-bait it out of sight of the subject and replace it one

287 minute after removal. From the moment the apparatus was placed back in the subject's

288 compartment, they had another ten minutes to solve the task again. If they were not

289 successful in a repeat trial, the session was ended. The apparatus was re-baited up to five more

290 times within a session (thus a maximum of six trials per session). Testing stopped either if a

291 subject reached criterion, which meant that the subject obtained rewards 12 times in a row in

292 two continuous sessions (6 successful trials per session), or they had six full, valid sessions with

293 no successful trials. If subjects had their first successful trial in the sixth session of testing then

294 they were given a seventh session to see if they would reach the successful criterion at this

295 point.

We considered a trial as unsuccessful, but valid, if the subjects touched either the

297 apparatus or stone tools at any point. Thus trials in which subjects did not approach the

298 apparatus or tools were counted as invalid. Testing sessions also ended after these invalid trials.

If subjects were unsuccessful in the pre-test, they were given the platform pushing

303 to give the subjects the opportunity to learn about the functional mechanism of the platform,

304 i.e. the collapsibility of the platform if force was exerted onto it, without providing any cues to 
305 the required problem solving behaviour if the target platform was out of reach, for example

306 dropping a stone tool onto it. They had to push down the platform directly with their beak to

307 release a reward. To this end, the apparatus had to be slightly modified to allow for this (Figure

1, A \& B). The subjects learned to push down the platform in the following way.

To begin with subjects were first provided with one 10-minute session to establish if they reach a criterion of pushing the platform twelve times in a row (with six trials a session).

314 the platform via shaping. Firstly, the magnets holding up the platform were weakened by

315 placing layers of tape between the magnet and the screws they magnetised to. Just touching

316 the platform was now enough to make it collapse. We gave them motivation to touch the

317 platform by placing a small reward (a single sunflower seed) on it. When they picked up this

318 reward, the platform collapsed and released the larger walnut reward from inside the

319 apparatus. If they succeeded, the apparatus was removed, re-baited and replaced five more

320 times for the subjects to repeat this behaviour (six in total). In the next session, the full magnet

321 strength was restored but the small reward was still placed in the pushing area. Six more

322 successes were required to pass this stage. Then, in the final sessions, the subjects had to push

323 the full strength platform without the small reward incentive. They had to do this 12 times in a

324 row in two sessions (six trials per session) to finally complete the platform pushing experience

325 and move on to the critical test phase (as described above). 


\section{$\underline{\text { Stick Transfer }}$}

Subjects would only proceed to this task if they had successfully completed the stonedropping task, in either the pre-test or the critical test. It used the same apparatus as the stone-dropping task except that the acrylic shell that enclosed the platform was moved $5 \mathrm{~cm}$

further forward (Figure 1 E\&F; supplementary video 4). This change meant that objects dropped into the tube on top of the apparatus would not automatically hit the platform. Instead, they had to insert a stick at an angle to make the end of the stick touch the platform. Dropping the sticks vertically would mean the sticks missed the platform, thus it wouldn't collapse and release a reward.

As these birds had never used a stick tool before, it was unclear what kind of stick would be easier for them to use, so we provided them with two different options. Both options were $18 \mathrm{~cm}$ long and made of aluminium, but one option was solid with a $0.8 \mathrm{~cm}$ diameter and the other option was hollow with a $2 \mathrm{~cm}$ diameter. The hollow stick was open at each end so that the macaws could place the end of their beak inside the stick; we thought this may have been an easier way for them to grasp the stick tool. To further make the stick tools easier to grip for the birds, they were wrapped with a single layer of silver duct tape. Additionally, multiple layers of black electrical tape were wrapped around each end of the sticks to make it harder for them to remove the duct tape from the sticks. Subjects were habituated to these sticks using the same protocol as used for the stone tools.

This task only consisted of a critical test phase as all the subjects that took part had experience of the mechanism of the platform from the stone-dropping task. Thus, the aim of 
347 this task was to evaluate if the birds could use the stick tool to produce the same result as in

348 the previous task. The procedure followed for this task was the same as the pre-test/critical

349 test method as the stone-dropping task.

All experiments were recorded on four static CCTV cameras. These covered all angles of the 
368 moment the apparatus was placed inside the testing chamber until the platform had collapsed.

369 Finally, we scored the number of times subjects dropped the stone and stick tools inside of the

370 apparatus in each trial. This final behaviour was counted from the time the apparatus was

371 placed inside the testing room until the moment the apparatus was removed from the testing

372 room, which included the 30 seconds after subjects had successfully dropped a stick or stone

373 tool onto the platform to make it collapse. 


\section{$375 \quad$ Results}

16 out of 18 subjects successfully and consistently dropped stones onto the platform

377 (Table 1; supplementary video 5 shows each individuals first innovation of the behaviour). The

378 other two birds, one of each species, never dropped any stones. Of the birds that succeeded,

379 eight reached the criterion in the pre-test phase and the other eight reached it in the critical

380 test phase (Figure 2). Of the birds that reached the criterion in the pre-test phase, seven were

381 A. ambiguus and one was an A. glaucogularis. Thus, those that succeeded in the critical test

phase were one $A$. ambiguus and seven A. glaucogularis.

The $A$. ambiguus spent significantly more time interacting with the stone tools (mean =

104 seconds, $\mathrm{sd}=69$ seconds) than the $A$. glaucogularis (mean $=40$ seconds, $\mathrm{sd}=22$ seconds)

in all trials before their first successful stone drop (Figure 3 ; Welch's two sample t-test, $t_{9.6}=$

$2.67, p=0.02)$. There were no significant differences between the two species in the other

387 exploratory measures; there was no difference between how much the two species interacted

388 with the apparatus nor was there a difference in time they spent touching the apparatus with a tool held in their beak.

After subjects' first successful stone drop, their latency to drop a stone in the following

391 trials greatly decreased (Figure 4, left). Additionally, all subjects began to drop more than one

392 stone in the trials following their first success (Figure 4, right; Table 2; supplementary video 4).

393 Subjects also showed a slight increase in the number of stones they placed on top of the

394 apparatus, but not inside the apparatus, on the trials after the first stone drop (Figure 5). 
396 tools to make the platform collapse (supplementary video 4). One more A. glaucogularis,

397 Charlie, had a single successful trial, but was unable to repeat this in subsequent trials. Four

398 more $A$. glaucogularis inserted the stick tools into the apparatus without hitting the platform

399 and none of the $A$. ambiguus ever inserted a stick tool into the apparatus. Only the two birds

400 that had a successful trial inserted the stick in more than one trial.

401

In total, the successful bird Mowgli inserted sticks into the apparatus 62 times and

402 obtained the reward from 15 of those cases. Charlie inserted sticks the second most number of

403 times, but he only did so five times, with one successful trial (Table 3).

405 (Figure 3). One A. ambiguus, Hazel, did not record a single valid trial as she learned how to

406 break the apparatus 
408

\section{Discussion}

16 out of 18 of parrots of both species were successful in innovating a novel tool use behaviour, i.e. stone-dropping, to solve a novel task (Table 1). The novel stone-dropping behaviour was within the behavioural capacity of both, however, there was a distinct difference between the two species. Seven out of eight of the successful Ara ambiguus, but only one Ara glaucogularis, solved the task in the pre-test phase, before they received the platform pushing experience, i.e. before they had learned anything about the causal mechanism of the collapsibility of the platform in the apparatus. However, seven out of the eight successful Ara glaucogularis and one Ara ambiguus solved the task only in the subsequent critical test phase, thus only after they had obtained information about the causal mechanism in the apparatus from the platform pushing experience (Figure 2). The different stages of the experiment at which the solution was innovated suggest that i) there were differences both between and within the species in what types of cognition they used to come up with the behavioural innovation and ii) the stone dropping test alone may not be diagnostic of the types of cognition used for the initial behavioural innovation, which will be discussed further in turn below. As almost all individuals were able to replicate the stone-dropping innovation after their initial success, it suggests that all the subjects at least understood the difference making causal effects of this behaviour. Moreover, the almost uniform failure of the subjects in the stick-test transfer task suggests that their understanding of the platform's collapsibility was inflexible and did not rely on an understanding of the mechanism. They were mostly unable to redirect a stick tool towards a platform in a different position. Nevertheless, a single individual was able 
429

430

431

432

433

434

to consistently succeed in this transfer task, showing that there are some conditions that may encourage these macaws to seek the underlying causal mechanism of an apparatus.

The original aim of this experiment was to examine whether an understanding of the functional mechanism of the task could underlie a subjects' problem solving performance in the stone dropping apparatus (Bird and Emery, 2009; von Bayern et al., 2009). In total, eight parrots (7 Ara glaucogularis, and 1 Ara ambiguus, Figure 2) were able to innovate the stone dropping behaviour after the platform pushing experience, similar to two out of four New Caledonian crows (von Bayern et al., 2009). The successful innovation of the behaviour at this stage suggests that the subjects had used a mechanistic understanding of how the platform required some form of force or contact to collapse, and had therefore dropped the stone onto it to recreate the force/contact they had previously exerted with their beaks.

The other eight successful parrots (7 Ara ambiguus and 1 Ara glaucogularis) were all successful in the pre-test phase of the experiment (Figure 2), prior to having any functional experience of the collapsibility of the platform within the apparatus. This was unexpected as it did not happen in the first iteration of this experiment with New Caledonian crows (von Bayern et al., 2009). At this stage, it was impossible for the parrots to be aware of the mechanics of the task because they had never observed the platform moving. For these parrots, the initial innovation of the solution was without a causal understanding of how the dropping stone would affect the platform; they could not have predicted the effect the stone would have. It is likely that these eight individuals innovated their solution through exploratory behaviour. 
This would suggest that Ara glaucogularis are more likely to need mechanistic solution and it may be that the Ara glaucogularis' causal understanding is more biased towards causal mechanisms (Johnson and Ahn, 2017). As the majority of the Ara ambiguus solved the task before getting to the mechanism information stage (the platform pushing), it would

454 suggest that they are perhaps more exploratory innovators. Nevertheless, a single individual

455 from both species solved the task in 'non species typical' way. This suggests that there are also 456 individual differences within the species, as one Ara glaucogularis appears to be an 'exploratory 457 innovator' and one Ara ambiguus appears to be a 'mechanistic innovator'. Both species appear 458 to have some flexibility in their innovation types. Furthermore, there was one individual of 459 both species that failed to innovate a solution at any stage, showing 'non-innovators' may also exist within both species (Table 2). of the experiment. For these individuals, it may be that they arrived at the solution through

463 increased intensity of exploring both the apparatus and tools available to them and 464 serendipitously discovered a beneficial object combination, namely placing the stone into the 465 tube and dropping it. Within the two species studied in this experiment the Ara ambiguus spent 466 significantly more time interacting with the stone tools than the Ara glaucogularis (Figure 3), 467 which may explain why the majority of the Ara ambiguus innovated stone-dropping in the pre468 test phase. There was no difference between the species in the other exploration measures we 469 took, regarding how much the individuals interacted with the apparatus both with their beak 470 and with the stone tools (Figure 3; Table 1). Also, based on these exploratory measures, the 
471 single Ara glaucogularis (Paco) that innovated the solution in the pre-test was not more

472 exploratory than his species peers, and the single Ara ambiguus (Enya) to not innovate the

473 solution in the pre-test was not less exploratory than her species peers (Table 1 ). Thus random

474 exploration may not be the explanatory factor for the individual differences in solution time. It

475 could be that the exploration was more directed, i.e. the subjects were given a stone and an

476 apparatus with a tube on the top and there was a fairly limited number of exploratory actions

477 they could have taken and placing the stone in the tube was one of them.

Highly explorative individuals have been shown to do better in problem solving tasks

479 previously (Overington et al., 2011). Macaws also have a diverse range of manipulative skills

(e.g. Villegas-Retana and Araya-H., 2017) like other parrots (Huber and Gajdon, 2006), which

481 are also important in creating novel exploration types, another factor vital in problem solving

482 (Griffin and Guez, 2014). Different species of parrots are thought to have different rates of

(Diopsittaca nobilis), shows reduced object-exploration intensity compared to New-Caledonian

488 New Caledonian crows in regards to haptic exploration (Auersperg et al., 2011), so it might be that the Ara ambiguus from this study share some ecological factors with the kea that select for increased haptic exploration and a tendency for creating object combinations, which most likely

491 explains why they produced the stone-dropping behaviour in pre-tests in contrast to the New

492 Caledonian crows (von Bayern et al., 2009). In corvids, one raven has previously been noted to 
arrive at the solution of the stone dropping task before having any experience of the platform collapsing before (Kabadayi and Osvath, 2017). Although these are typically neophobic birds (Heinrich, 1988) they are still exploratory once they have overcome their neophobia (O'Hara et al., 2017).

In order to obtain a direct comparison of the object exploration tendencies of the two macaw species tested here with that of the previously tested New Caledonian crows, ravens and other birds, it would be informative to study their object-combination tendencies as described in Auersperg et al. (2015). We do not know much about their ecology in the wild nor their drive to explore, but it appears that the Ara glaucogularis are fairly reliant on a single food source (palm fruits) (Collar et al., 2019b; Yamashita and Machado de Barros, 1997) whereas Ara ambiguus are forced to search for variable food sources for two months of the year when their preferred food source (mountain almond trees) is not in season (Berg et al., 2007; Collar et al., 2019a). This may have selected for an increased exploratory tendency in Ara ambiguus compared to Ara glaucogularis and may explain why more of the Ara ambiguus discovered the stone dropping solution during the pre-test stage.

If some subjects, regardless of species, were able to innovate the stone-dropping behaviour without the platform-pushing experience, then it is possible that the subjects that required the platform-pushing experience did not specifically gain mechanistic information from the platform-pushing. Rather than learning something about the mechanism during this phase, the platform pushing may have served to more simply create a positive valence for the whole apparatus, i.e. the subjects recognised it was a potentially reward giving object. This could have encouraged the subjects to explore it further, and thus it may have been exploration 
515 that ultimately led them to place stones into the tube, not a mechanism based causal

516 understanding. Thus, the subjects that discovered the solution after the platform-pushing

517 experience may have also discovered the solution by chance, but just taking more time as they

518 were less explorative than the subjects that discovered the solution before the platform

519 pushing. To control for this possibility, it would be good to add another control group that

520 instead of the platform pushing experience were given a similar number of sessions to consume

521 rewards from the apparatus at the same phase of the experiment. If this control group also

522 innovate the stone-dropping, then it suggests that there was no mechanistic understanding

523 involved, but a local enhancement of the apparatus encouraging exploration.

525 across both species appeared to recognise and remember which aspect of their own behaviour

526 had led to the reward from the moment they had first solved the task i.e. dropped a stone in

527 the tube for the very first time. All birds that innovated once were able to consistently repeat

528 the behaviour (Table 2). Four birds had a single failed trial after their first success, and the rest

529 had zero failed trials (Table 2). Additionally, the speed with which the behaviour was repeated

530 suggests rapid learning (Figure 4). This strongly suggests that the parrots recognised which of

531 their own actions had influenced their environment, even if their initial behaviour had come

532 from accidental exploration. They recognised the difference making properties this tool had

533 had on the apparatus (Woodward, 2011). However, after the subjects' first successful stone-

534 drop, there was also a small peak in erroneous stone placement behaviour in some subjects

535 (Figure 5). The subjects increased the number of times they placed stones on top of the

536 apparatus, but not inside the open hole to the platform, in the trials immediately after their 
537 first success. This suggests that the subjects perhaps only recognised a more general behaviour

538 involving both the stone and the apparatus was important to creating the desired effect and

539 still needed some trial and error before recognising the exact behaviour of placing the stone

540 inside the open hole above the platform.

Further evidence that the subjects perhaps did not fully understand the mechanism of

542 the apparatus comes from the almost uniform failure in the stick test transfer. Only five of the

543 subjects inserted the sticks into the apparatus, all of them were Ara glaucogularis and only two

544 did so in more than one trial (Table 3). The majority of subjects did not appear to be able to

545 flexibly transfer their knowledge of dropping stones into the apparatus to dropping a stick into

546 the apparatus. Most of the subjects that did insert a stick into the apparatus did not do so

547 persistently as for most of them it did not lead to the platform collapsing, as the platform had

548 now been moved from directly underneath the tube. Interestingly, none of the subjects that

549 solved the stone dropping task in the pre-test ever inserted a stick into the apparatus. It could

550 be that those that required knowledge of the mechanism to solve the task gained a more

551 flexible causal understanding of the apparatus, hence they were more flexible in what kind of

552 tool to try and insert into the apparatus. However, based on personal observations of the stick-

553 test, it was apparent that the subjects struggled to handle the stick tools, and this may have

554 been the underlying factor for why most subjects did not insert them into the tube.

The single subject that did succeed in multiple trials, Mowgli, was not very consistent in

556 producing the successful behaviour. He required many attempted insertions and many failed

557 'drops' of the stick tool before he could make it consistently come into contact with the

558 platform (see supplementary video 4 for an example). Previous research has shown that 
persistence is a key factor in problem-solving tasks (Chow et al., 2016; Thornton and Samson, 2012), and it is presumably Mowgli's persistence that allowed him to succeed as he was the only one to repeatedly attempt to use the stick tool (Table 3). None of the macaws were able to use the sticks as a skilled tool user would: by holding one end of it and directing the distal end of the stick in the desired direction. Instead, they used it as an awkwardly shaped stone, dropping the proximal end they were holding vertically into the tube. This did not give the macaws much control over the stick, ergo it was probably very difficult for them to direct the stick towards the moved platform. Nevertheless, Mowgli's skill with the stick appeared to improve across the course of his trials and he required fewer attempts to drop the stick onto the platform before succeeding in later trials (Table 3). This would suggest that he had paid attention to the detail that the platform had moved as he was directing the sticks towards the new position of the platform and not simply dropping the stick into the tube undirected. It's possible he had a mental representation that he had to create contact between the tool and the platform, which in turn suggests he was using a mental representation of part of the causal mechanism of the task. However, Mowgli was the only individual that showed this possibility. Thus the overwhelming evidence from the other subjects is that they do not have a drive to use causal mechanisms to solve problem-solving tasks.

There is other evidence that suggests the subjects appear to have not quite understood exactly how the stone-tool influenced the moveable platform. All of the subjects that started stone dropping also began to drop more than one stone in the following trials (Figure 4, right; see supplementary video 3 for example). This behaviour suggests the subjects did not make the connection that the stone they had dropped had impacted the platform, which in turn 
581

582

583

584

585

586

587

588

589

590

591

592

593

594

595

596

597

598

599

600

601

602

made it collapse. Instead, it suggests they may have been trying to get more rewards from an apparatus that had already released its reward. This mistake implies the subjects only recognised that dropping the stone in the hole led to a reward, not how or why it did. This behaviour could also be explained by a lack of inhibitory control as it had become a conditioned behaviour (Kabadayi et al., 2017) . Equally, the repeated stone dropping may have been additional play and exploratory behaviour, which as discussed above, could be the reason they found the solution in the first place, and probably a hard behaviour to suppress.

In conclusion, there is strong evidence that these macaws are good problem-solvers as the majority were able to innovate a tool-using solution to the stone-dropping task, i.e. they were able to drop a stone onto a collapsible platform. There is some evidence to suggest that some subjects, mostly Ara glaucogularis, used a causal understanding of the mechanism underlying the apparatus, the collapsible platform, to innovate the initial stone-dropping solution. There is also evidence to suggest that most of the Ara ambiguus used exploratory behaviour to discover the stone-dropping innovation. Nevertheless, all subjects displayed an understanding of which of their behaviours had been critical in making the platform collapse as all of them were able to rapidly and consistently repeat their stone-dropping innovations. Thus they all displayed a difference-making, learned, causal understanding of their behaviour. Most of the subjects had difficulties in handling stick tools in the transfer task, but one Ara glaucogularis individual was able to succeed in this task, which gave stronger evidence that he had used an understanding of the underlying mechanism to innovate the use of the tools to collapse the platform. 


\section{Ethical Statement}

604 All applicable international, national, and institutional guidelines for the care and use of animals

605 were followed. In accordance with the German Animal Welfare Act of 25th May 1998, Section

606 V, Article 7 and the Spanish Animal Welfare Act 32/2007 of 7th November 2007, Preliminary

607 Title, Article 3, the study was classified as non-animal experiment and did not require any

608 approval from a relevant body.

609

610 Supplementary data and videos

611 Data from the video coding and Supplementary videos can be found on figshare at:

612 https://doi.org/10.6084/m9.figshare.12800768.v1

\section{Author Contributions}

615 The design of the experiment was initially conceived by LO'N and AvB, with contributions from

616 AP and NB. The experiments were carried out by AP, NB and RH. Videos were coded by RH and

617 data were visualised by LO'N. The initial manuscript was written by LO'N with feedback from

$618 \quad A v B$ and MG.

619 Acknowledgements

620 We thank Magdalena van Buuren \& Luisana Carballo for their comments on earlier versions of 621 the manuscript. 
622 We thank the Loro Parque and its president, Mr Wolfgang Kiessling for their support, the access

623 to the birds and the research facilities. We thank the Loro Parque Fundación and its president

624 Mr Christoph Kiessling for their collaboration and the staff of the Loro Parque Fundación, the

625 animal caretakers and the veterinary department for their support.

626 LO'N is a member of the International Max Planck Research School (IMPRS) for Organismal

627 Biology. The study was funded by the Max-Planck Society. 


\section{References}

Auersperg, A., von Bayern, A., Gajdon, G., Huber, L., Kacelnik, A., 2011. Flexibility in Problem Solving and Tool Use of Kea and New Caledonian Crows in a Multi Access Box Paradigm. PLoS ONE 6, e20231. https://doi.org/10.1371/journal.pone.0020231

Auersperg, A.M.I., Huber, L., Gajdon, G.K., 2011. Navigating a tool end in a specific direction: stick-tool use in kea (Nestor notabilis). Biol. Lett. 7, 825-828. https://doi.org/10.1098/rsbl.2011.0388

Auersperg, A.M.I., Szabo, B., von Bayern, A.M.P., Kacelnik, A., 2012. Spontaneous innovation in tool manufacture and use in a Goffin's cockatoo. Curr. Biol. 22, R903-R904. https://doi.org/10.1016/j.cub.2012.09.002

Auersperg, A.M.I., van Horik, J.O., Bugnyar, T., Kacelnik, A., Emery, N.J., von Bayern, A.M.P., 2015. Combinatory actions during object play in psittaciformes (Diopsittaca nobilis, Pionites melanocephala, Cacatua goffini) and corvids (Corvus corax, C. monedula, C. moneduloides). J. Comp. Psychol. 129, 62-71. https://doi.org/10.1037/a0038314

Berg, K.S., Socola, J., Angel, R.R., 2007. Great Green Macaws and the annual cycle of their food plants in Ecuador. J. Field Ornithol. 78, 1-10. https://doi.org/10.1111/j.1557-9263.2006.00080.x

Bird, C.D., Emery, N.J., 2009. Insightful problem solving and creative tool modification by captive nontool-using rooks. Proc. Natl. Acad. Sci. 106, 10370-10375. https://doi.org/10.1073/pnas.0901008106

Chow, P.K.Y., Lea, S.E.G., Leaver, L.A., 2016. How practice makes perfect: the role of persistence, flexibility and learning in problem-solving efficiency. Anim. Behav. 112, 273-283. https://doi.org/10.1016/j.anbehav.2015.11.014

Collar, N., Boesman, P., Sharpe, C.J., 2019a. Great Green Macaw (Ara ambiguus).

Collar, N., Boesman, P., Sharpe, C.J., del Hoyo, J., Elliott, A., Sargatal, J., Christie, D.A., de Juana, E., 2019b. Blue-throated Macaw (Ara glaucogularis), in: Handbook of the Birds of the World Alive. Lynx Editions.

Emery, N.J., Clayton, N.S., 2004. The Mentality of Crows: Convergent Evolution of Intelligence in Corvids and Apes. Science 306, 1903-1907. https://doi.org/10.1126/science.1098410

Goodman, M., Hayward, T., Hunt, G.R., 2018. Habitual tool use innovated by free-living New Zealand kea. Sci. Rep. 8, 13935. https://doi.org/10.1038/s41598-018-32363-9

Griffin, A.S., Guez, D., 2014. Innovation and problem solving: A review of common mechanisms. Behav. Processes 109, 121-134. https://doi.org/10.1016/j.beproc.2014.08.027

Gutiérrez-Ibáñez, C., Iwaniuk, A.N., Wylie, D.R., 2018. Parrots have evolved a primate-like telencephalicmidbrain-cerebellar circuit. Sci. Rep. 8, 9960. https://doi.org/10.1038/s41598-018-28301-4

Hanus, D., 2016. Causal reasoning versus associative learning: A useful dichotomy or a strawman battle in comparative psychology? J. Comp. Psychol. 130, 241-248. https://doi.org/10.1037/a0040235

Heinrich, B., 1988. Why Do Ravens Fear Their Food? The Condor 90, 950-952. https://doi.org/10.2307/1368859

Heinsohn, R., Zdenek, C.N., Cunningham, R.B., Endler, J.A., Langmore, N.E., 2017. Tool-assisted rhythmic drumming in palm cockatoos shares key elements of human instrumental music. Sci. Adv. 3, e1602399. https://doi.org/10.1126/sciadv.1602399 
669

670

671

672

673

674

675

676

677

678

679

680

681

682

683

684

685

686

687

688

689

690

691

692

693

694

695

696

697

698

699

700

701

702

703

704

705

706

707

708

709

Herculano-Houzel, S., 2017. Numbers of neurons as biological correlates of cognitive capability. Curr. Opin. Behav. Sci. 16, 1-7. https://doi.org/10.1016/j.cobeha.2017.02.004

Huber, L., Gajdon, G.K., 2006. Technical intelligence in animals: the kea model. Anim. Cogn. 9, 295-305. https://doi.org/10.1007/s10071-006-0033-8

Iwaniuk, A.N., Dean, K.M., Nelson, J.E., 2005. Interspecific Allometry of the Brain and Brain Regions in Parrots (Psittaciformes): Comparisons with Other Birds and Primates. Brain. Behav. Evol. 65, 4059. https://doi.org/10.1159/000081110

Johnson, S.G.B., Ahn, W., 2017. Causal Mechanisms. Oxford University Press. https://doi.org/10.1093/oxfordhb/9780199399550.013.12

Kabadayi, C., Krasheninnikova, A., O’Neill, L., van de Weijer, J., Osvath, M., von Bayern, A.M.P., 2017. Are parrots poor at motor self-regulation or is the cylinder task poor at measuring it? Anim. Cogn. 20, 1137-1146. https://doi.org/10.1007/s10071-017-1131-5

Kabadayi, C., Osvath, M., 2017. Ravens parallel great apes in flexible planning for tool-use and bartering. Science 357, 202-204. https://doi.org/10.1126/science.aam8138

Kacelnik, A., 2009. Tools for thought or thoughts for tools? Proc. Natl. Acad. Sci. 106, 10071-10072. https://doi.org/10.1073/pnas.0904735106

Krasheninnikova, A., Berardi, R., Lind, M.-A., O'Neill, L., von Bayern, A.M.P., 2019. Primate cognition test battery in parrots. Behaviour 1-41. https://doi.org/10.1163/1568539X-0003549

Kumar, S., Stecher, G., Suleski, M., Hedges, S.B., 2017. TimeTree: A Resource for Timelines, Timetrees, and Divergence Times. Mol. Biol. Evol. 34, 1812-1819. https://doi.org/10.1093/molbev/msx116

Lambert, M.L., Jacobs, I., Osvath, M., von Bayern, A.M.P., 2018. Birds of a feather? Parrot and corvid cognition compared. Behaviour 1-90. https://doi.org/10.1163/1568539X-00003527

Le Pelley, M.E., Griffiths, O., Beesley, T., 2017. Associative Accounts of Causal Cognition. Oxford University Press. https://doi.org/10.1093/oxfordhb/9780199399550.013.2

Lefebvre, L., Whittle, P., Lascaris, E., Finkelstein, A., 1997. Feeding innovations and forebrain size in birds. Anim. Behav. 53, 549-560. https://doi.org/10.1006/anbe.1996.0330

Mettke-Hofmann, C., Winkler, H., Leisler, B., 2002. The Significance of Ecological Factors for Exploration and Neophobia in Parrots. Ethology 108, 249-272. https://doi.org/10.1046/j.14390310.2002.00773.x

Neilands, P.D., Jelbert, S.A., Breen, A.J., Schiestl, M., Taylor, A.H., 2016. How Insightful Is 'Insight'? New Caledonian Crows Do Not Attend to Object Weight during Spontaneous Stone Dropping. PLOS ONE 11, e0167419. https://doi.org/10.1371/journal.pone.0167419

O’Hara, M., Mioduszewska, B., von Bayern, A., Auersperg, A., Bugnyar, T., Wilkinson, A., Huber, L., Gajdon, G.K., 2017. The temporal dependence of exploration on neotic style in birds. Sci. Rep. 7, 4742. https://doi.org/10.1038/s41598-017-04751-0

Olkowicz, S., Kocourek, M., Lučan, R.K., Porteš, M., Fitch, W.T., Herculano-Houzel, S., Němec, P., 2016. Birds have primate-like numbers of neurons in the forebrain. Proc. Natl. Acad. Sci. 113, 72557260. https://doi.org/10.1073/pnas.1517131113

O’Neill, L., Picaud, A., Maehner, J., Gahr, M., von Bayern, A.M.P., 2018. Two macaw species can learn to solve an optimised two-trap problem, but without functional causal understanding. Behaviour 1-30. https://doi.org/10.1163/1568539X-00003521 
Osuna-Mascaró, A.J., Auersperg, A.M.I., 2018. On the brink of tool use? Could object combinations during foraging in a feral Goffin's cockatoo (Cacatua goffiniana) result in tool innovations? Anim. Behav. Cogn. 5, 229-234. https://doi.org/10.26451/abc.05.02.05.2018

Osvath, M., Kabadayi, C., Jacobs, I., 2014. Independent Evolution of Similar Complex Cognitive Skills: The Importance of Embodied Degrees of Freedom. Anim. Behav. Cogn. 1, 249. https://doi.org/10.12966/abc.08.03.2014

Overington, S.E., Cauchard, L., Côté, K.-A., Lefebvre, L., 2011. Innovative foraging behaviour in birds: What characterizes an innovator? Behav. Processes 87, 274-285. https://doi.org/10.1016/j.beproc.2011.06.002

Povinelli, D.J., 2000. Folk physics for apes: the chimpanzee's theory of how the world works, Dig. print. (repr. 2008). ed. Oxford Univ. Press, Oxford.

Sol, D., Duncan, R.P., Blackburn, T.M., Cassey, P., Lefebvre, L., 2005. Big brains, enhanced cognition, and response of birds to novel environments. Proc. Natl. Acad. Sci. 102, 5460-5465. https://doi.org/10.1073/pnas.0408145102

Sol, D., Székely, T., Liker, A., Lefebvre, L., 2007. Big-brained birds survive better in nature. Proc. R. Soc. B Biol. Sci. 274, 763-769. https://doi.org/10.1098/rspb.2006.3765

Sol, D., Timmermans, S., Lefebvre, L., 2002. Behavioural flexibility and invasion success in birds. Anim. Behav. 63, 495-502. https://doi.org/10.1006/anbe.2001.1953

Thornton, A., Samson, J., 2012. Innovative problem solving in wild meerkats. Anim. Behav. 83, 14591468. https://doi.org/10.1016/j.anbehav.2012.03.018

Toft, C.A., Wright, T.F., Gilardi, J.D., 2016. Parrots of the wild: a natural history of the world's most captivating birds.

Van Horik, J.O., Clayton, N.S., Emery, N.J., 2012. Convergent Evolution of Cognition in Corvids, Apes and Other Animals. Oxford University Press. https://doi.org/10.1093/oxfordhb/9780199738182.013.0005

Villegas-Retana, S.A., Araya-H., D., 2017. Consumo de almendro de playa (Terminalia catappa) y uso de hojas como herramienta por parte del ave Ara ambiguus (Psittaciformes: Psittacidae) en Costa Rica. UNED Res. J. 9. https://doi.org/10.22458/urj.v9i2.1894

von Bayern, A.M.P., Heathcote, R.J.P., Rutz, C., Kacelnik, A., 2009. The Role of Experience in Problem Solving and Innovative Tool Use in Crows. Curr. Biol. 19, 1965-1968. https://doi.org/10.1016/j.cub.2009.10.037

Wood, G.A., 1984. Tool use by the Palm Cockatoo Probosciger aterrimus during display. Corella 8, 9495.

Woodward, J., 2011. A Philosopher Looks at Tool Use and Causal Understanding, in: Tool Use and Causal Cognition. Oxford University Press.

Wright, T.F., Schirtzinger, E.E., Matsumoto, T., Eberhard, J.R., Graves, G.R., Sanchez, J.J., Capelli, S., Müller, H., Scharpegge, J., Chambers, G.K., Fleischer, R.C., 2008. A Multilocus Molecular Phylogeny of the Parrots (Psittaciformes): Support for a Gondwanan Origin during the Cretaceous. Mol. Biol. Evol. 25, 2141-2156. https://doi.org/10.1093/molbev/msn160 
bioRxiv preprint doi: https://doi.org/10.1101/2020.08.24.264390; this version posted August 24, 2020. The copyright holder for this preprint

(which was not certified by peer review) is the author/funder, who has granted bioRxiv a license to display the preprint in perpetuity. It is made available under aCC-BY-NC-ND 4.0 International license.

749 Yamashita, C., Machado de Barros, Y., 1997. The Blue-throated Macaw Ara glaucogularis:

$750 \quad$ characterisation of its distinctive habitats in savannahs of the Beni, Bolivia. Ararajuba 5, 141-

751

150.

752

753 


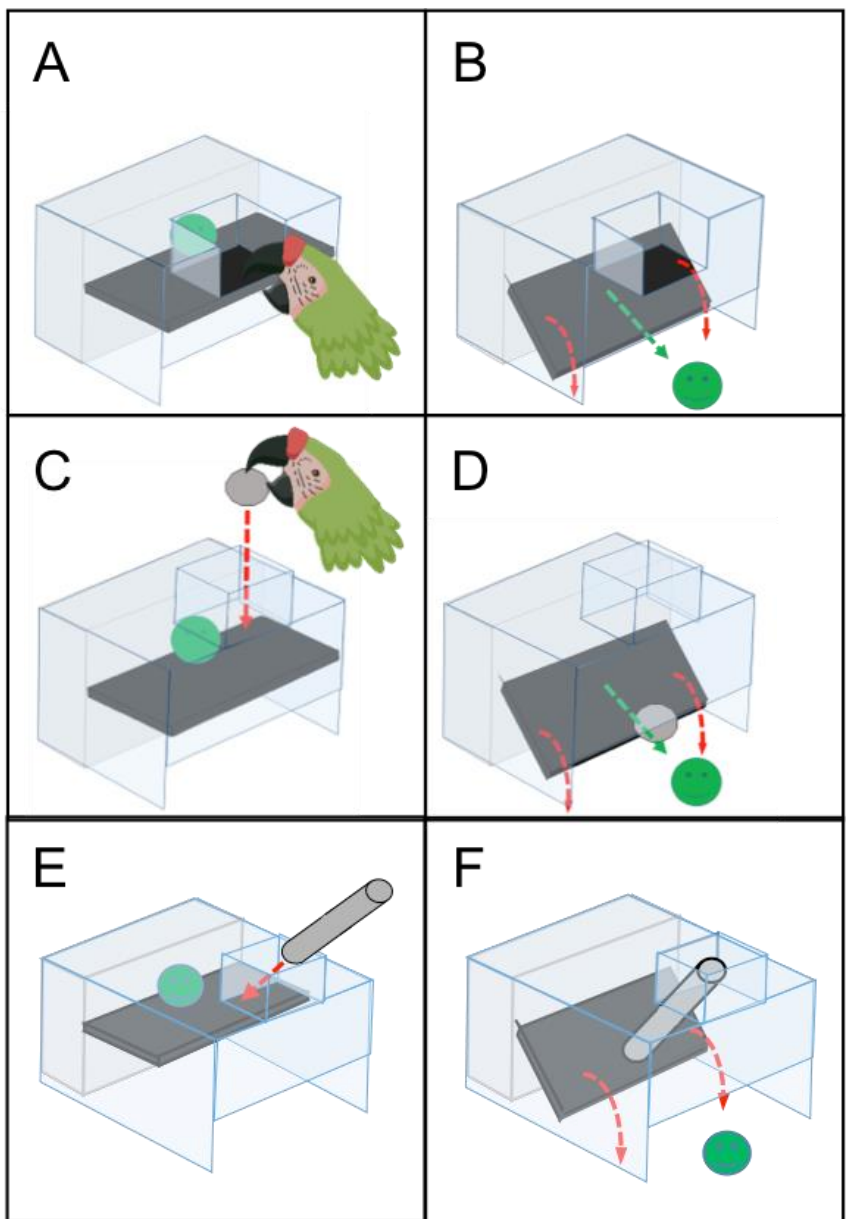

Figure 1 All of the apparatus used in the stone dropping test, the platform pushing pushing experience. In this stage, subjects could push the black platform (A) causing it to detach from a pair of magnets and allowing a reward to fall out the bottom (B). C\&D show the apparatus setup for the pre-test and critical test phases of stone dropping task, which occurred before and after the platform pushing experience respectively. In these stages, the subjects could only make the platform collapse by dropping a stone through the tube in the top of the apparatus (c), to release a reward (D). E\&F show the stick transfer task, in which the transparent acrylic shell was extended so that the tube was no longer directly above the platform. This meant that a stick had to be inserted at an angle into the tube (E) so that it touched the platform (F). 


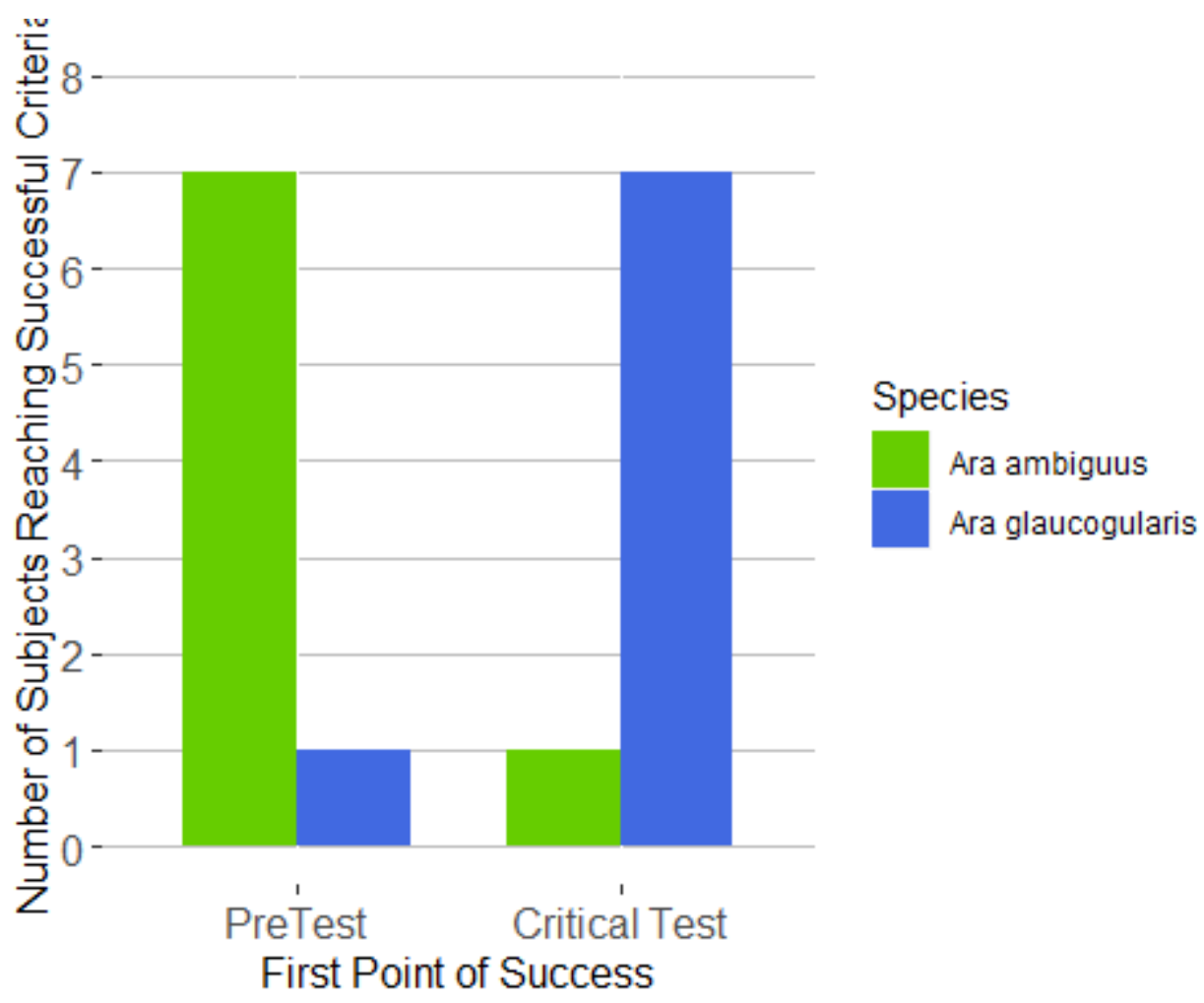

771 Figure 2. The Number of Subjects successfully passing the stone dropping task at each stage.

772 Many birds were able to pass the stone dropping test from both species. However there were 773 differences between the two species as to what stage they could pass the test. The majority of 774 the Ara ambiguus were able to complete the task in the pre-test phase, whereas the majority of 775 the Ara glaucogularis only completed the task in the Critical Test Phase. Two birds, one of each 776 species, failed the task. 


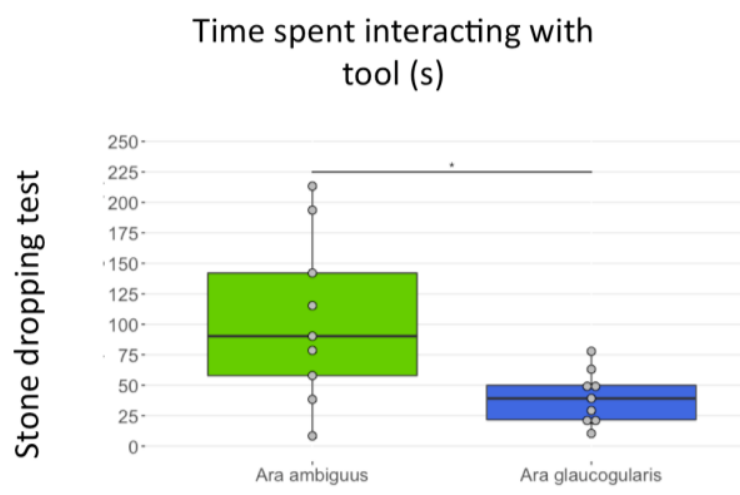

Time spent interacting with apparatus (s)
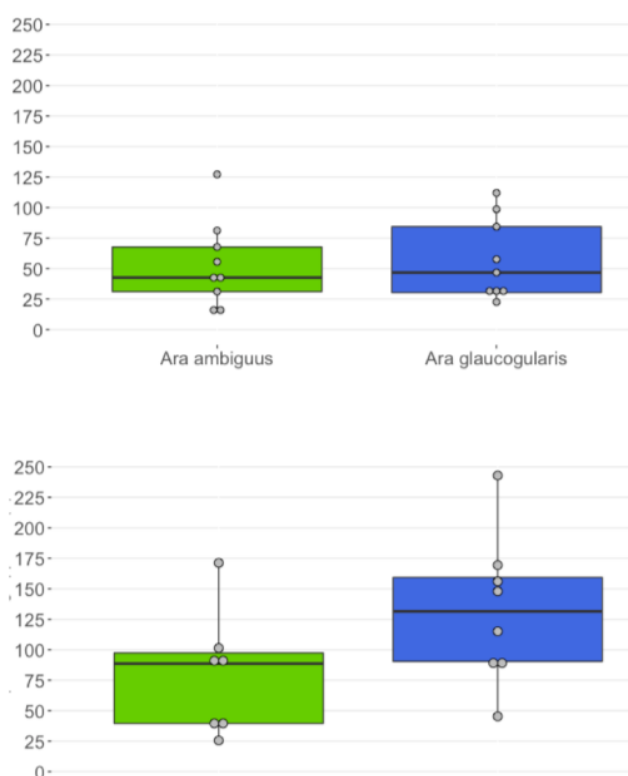

Ara ambiguus

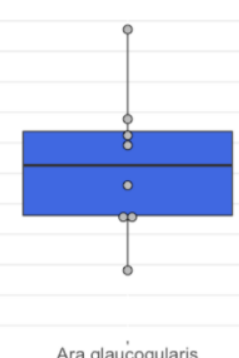

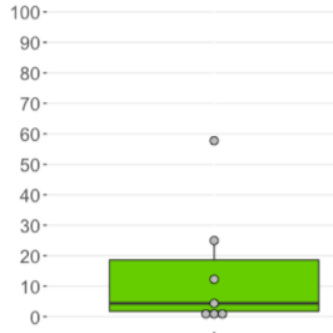

Ara ambiguus
Time spent interacting with apparatus using the tool (s)
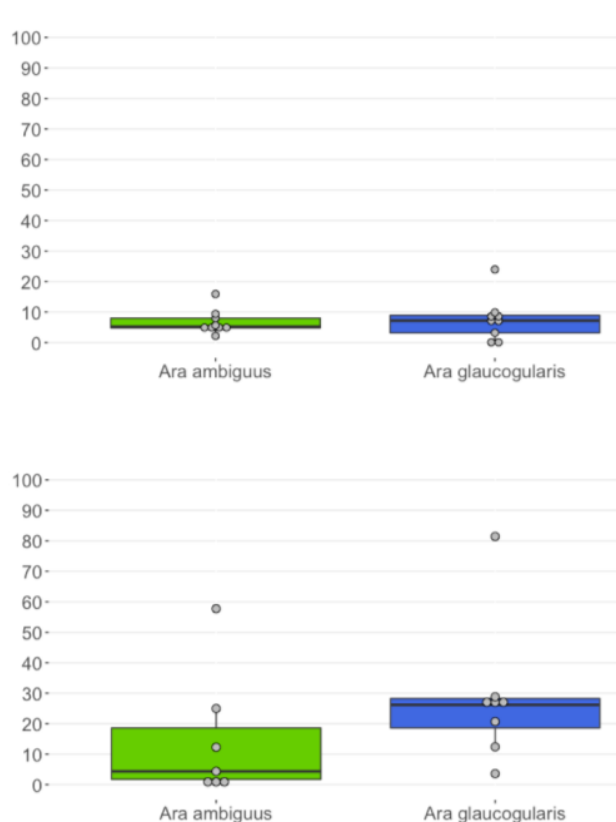

Figure 3 The average amount of time individuals spent interacting with the tools, the apparatus and a combination of both during both the initial stone dropping test and the stick test transfer. Only the trials prior to their first success are shown, as these are the only trials in which the birds were 'exploring', thus for the stone dropping task, the data shows a combination of pre-test and critical test trial data if subjects did not succeed until the critical test. The combination data (the two graphs on the right) shows the amount of time the subjects were specifically touching the apparatus with a tool being held in their beak. 


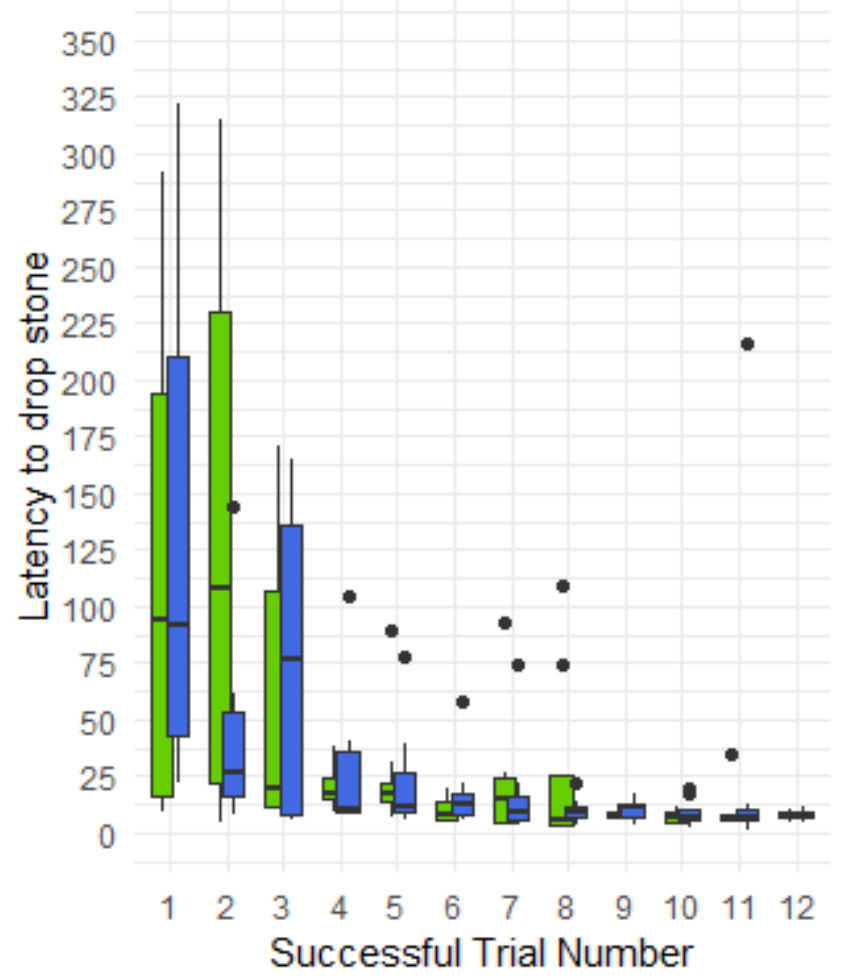

787

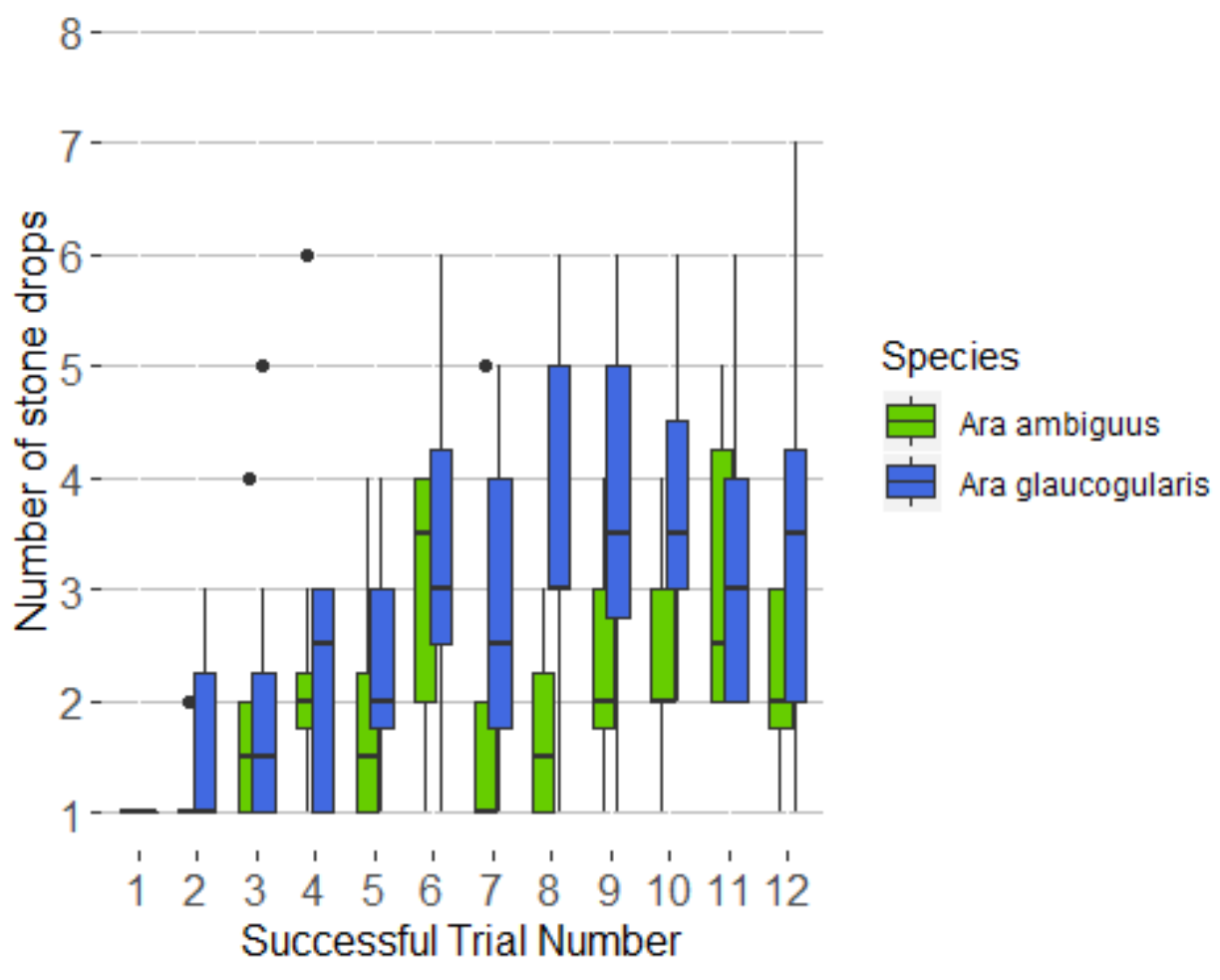

Figure 4. The Subjects behaviour after first success with stone dropping apparatus. After their first successful trial, subjects' latency to repeat the successful stone dropping behaviour reduced in following trials. They also started increasing the number of stones that they dropped into the apparatus within each trial. 

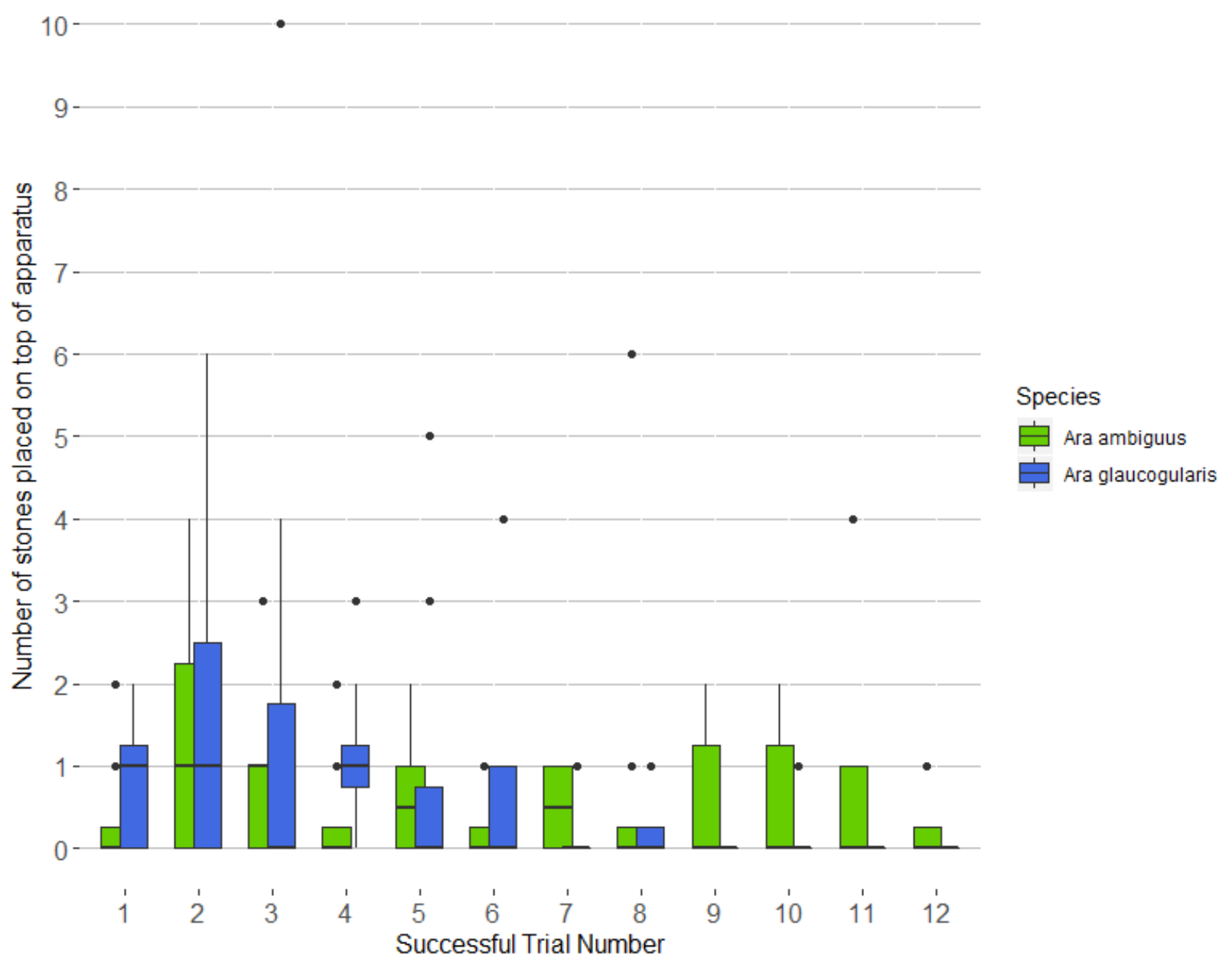

Figure 5 The number of times subjects placed stones on top of the apparatus, but not inside the box. There was a slight peak of placing stones on top of the apparatus, and not inside the box, after the first successful stone-drop. This is suggestive of the subjects recognising they had completed an action that involved the stone and the apparatus, but not specifically placing the stone inside the apparatus. 


\begin{tabular}{|c|c|c|c|c|c|c|c|c|c|c|}
\hline Subject & Species & Sex & $\begin{array}{c}\text { Age } \\
\text { (years) }\end{array}$ & $\begin{array}{c}\text { First } \\
\text { Pretest } \\
\text { success } \\
\text { trial }\end{array}$ & $\begin{array}{c}\text { First } \\
\text { Critical } \\
\text { Test } \\
\text { success } \\
\text { trial }\end{array}$ & $\begin{array}{l}\text { Latency } \\
\text { to touch } \\
\text { stone }\end{array}$ & $\begin{array}{l}\text { Duration } \\
\text { touching } \\
\text { stone }\end{array}$ & $\begin{array}{l}\text { Latency } \\
\text { to touch } \\
\text { apparatus }\end{array}$ & $\begin{array}{l}\text { Duration } \\
\text { touching } \\
\text { apparatus }\end{array}$ & $\begin{array}{c}\text { Duration } \\
\text { touching } \\
\text { apparatus } \\
\text { with } \\
\text { stone }\end{array}$ \\
\hline Acorn & ambiguus & Female & 4 & 4 & - & 6.60 & 78.53 & 16.07 & 31.13 & 8.00 \\
\hline Alba & ambiguus & Female & 3 & Fail & Fail & 23.45 & 90.20 & 71.75 & 81.12 & 5.20 \\
\hline Enya & ambiguus & Female & 3 & Fail & 3 & 89.27 & 38.40 & 96.91 & 42.67 & 4.80 \\
\hline Hagrid & ambiguus & Male & 3 & 1 & - & 25.40 & 8.40 & 9.40 & 17.80 & 2.20 \\
\hline Hazel & ambiguus & Female & 6 & 4 & - & 4.53 & 115.27 & 27.80 & 127.20 & 15.93 \\
\hline Luna & ambiguus & Female & 3 & 6 & - & 2.10 & 142.00 & 87.93 & 55.53 & 5.67 \\
\hline Madame & ambiguus & Female & 3 & 5 & - & 12.68 & 193.60 & 19.47 & 42.44 & 5.12 \\
\hline Rita & ambiguus & Female & 3 & 6 & - & 2.87 & 213.30 & 65.40 & 67.70 & 9.40 \\
\hline Shouty & ambiguus & Female & 11 & 6 & - & 17.48 & 57.88 & 80.96 & 14.24 & 4.64 \\
\hline Captain & glaucogularis & Male & 9 & Fail & 6 & 103.22 & 29.16 & 49.07 & 30.33 & 6.96 \\
\hline Charlie & glaucogularis & Male & 3 & Fail & 1 & 201.23 & 48.13 & 200.90 & 29.73 & 9.90 \\
\hline Gargamel & glaucogularis & Male & 5 & Fail & 5 & 22.48 & 20.40 & 25.78 & 33.35 & 0.20 \\
\hline Hannibal & glaucogularis & Male & 6 & Fail & Fail & 166.63 & 49.97 & 70.27 & 84.33 & 0.00 \\
\hline Lady & glaucogularis & Female & 3 & Fail & 2 & 194.58 & 21.60 & 215.18 & 98.63 & 7.23 \\
\hline LongJohn & glaucogularis & Male & 4 & Fail & 3 & 28.29 & 77.77 & 49.20 & 111.97 & 23.97 \\
\hline Mowgli & glaucogularis & Male & 3 & Fail & 2 & 16.37 & 39.17 & 8.46 & 46.74 & 8.97 \\
\hline MrHuang & glaucogularis & Male & 4 & Fail & 3 & 100.49 & 63.07 & 76.29 & 57.60 & 8.20 \\
\hline Paco & glaucogularis & Male & 3 & 1 & - & 12.60 & 10.40 & 1.80 & 22.60 & 3.20 \\
\hline
\end{tabular}

817 Table 1 Description of subjects and their success in the stone dropping task. 'Fail' indicates that the subjects completed six sessions

818 of the given phase without reaching the successful criteria. Numbers indicate the session in which subjects had their first successful

819 trial. Dashes indicate that the subject did not do the phase because they had already succeeded in the experiment. The five columns 820 on the right indicate individuals average exploration times (in seconds) in trials up until, and including, their first successful trial. 


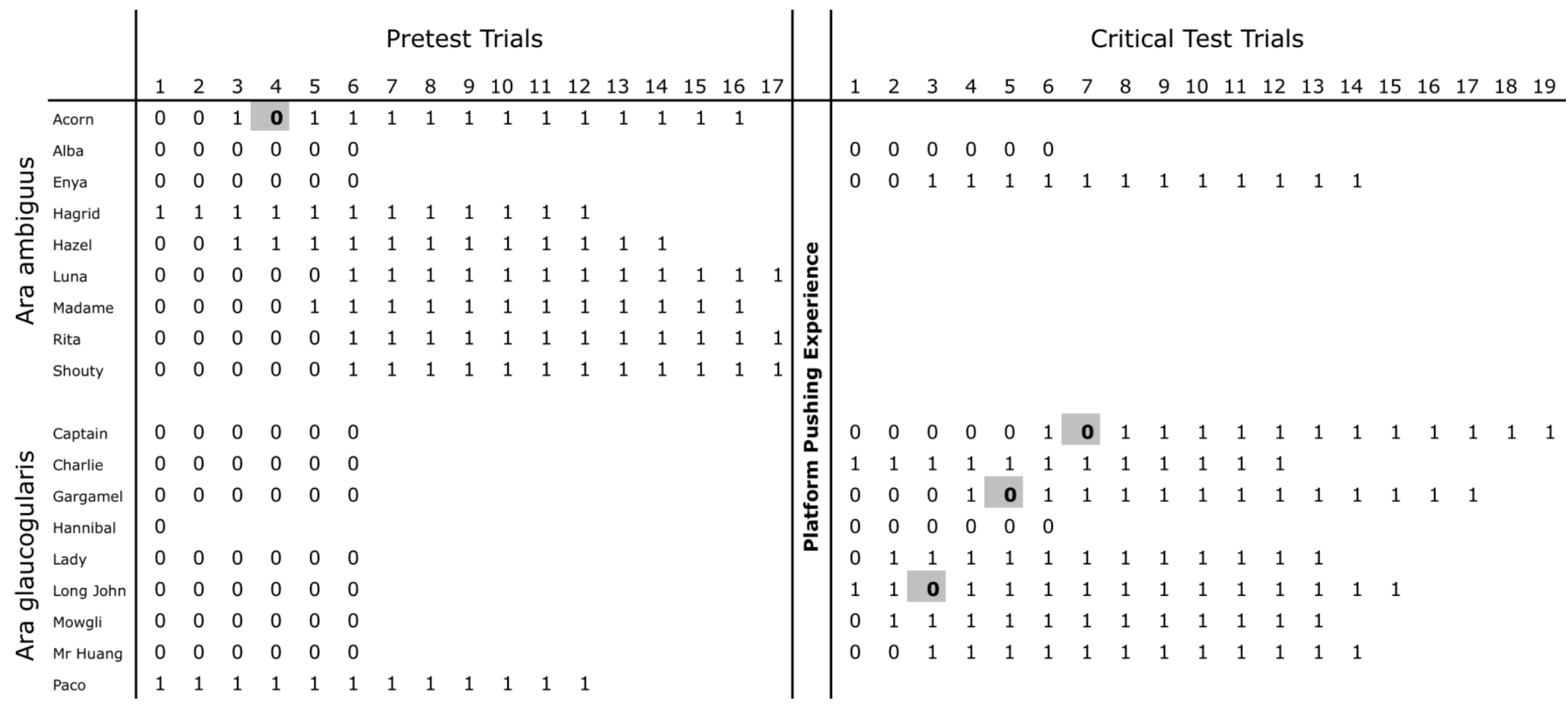

Table 2. The subjects success across trials in the experiment, showing which subjects succeeded in the pre-test trials and which succeeded in the critical test trials. 0 denotes a failed trial and 1 denotes a successful trial. Trials in which subjects failed after a successful trial are highlighted. Hannibal only recorded one valid pre-test trial, however he had 10 invalid pre-test trials, so he moved onto the experience phase regardless. 


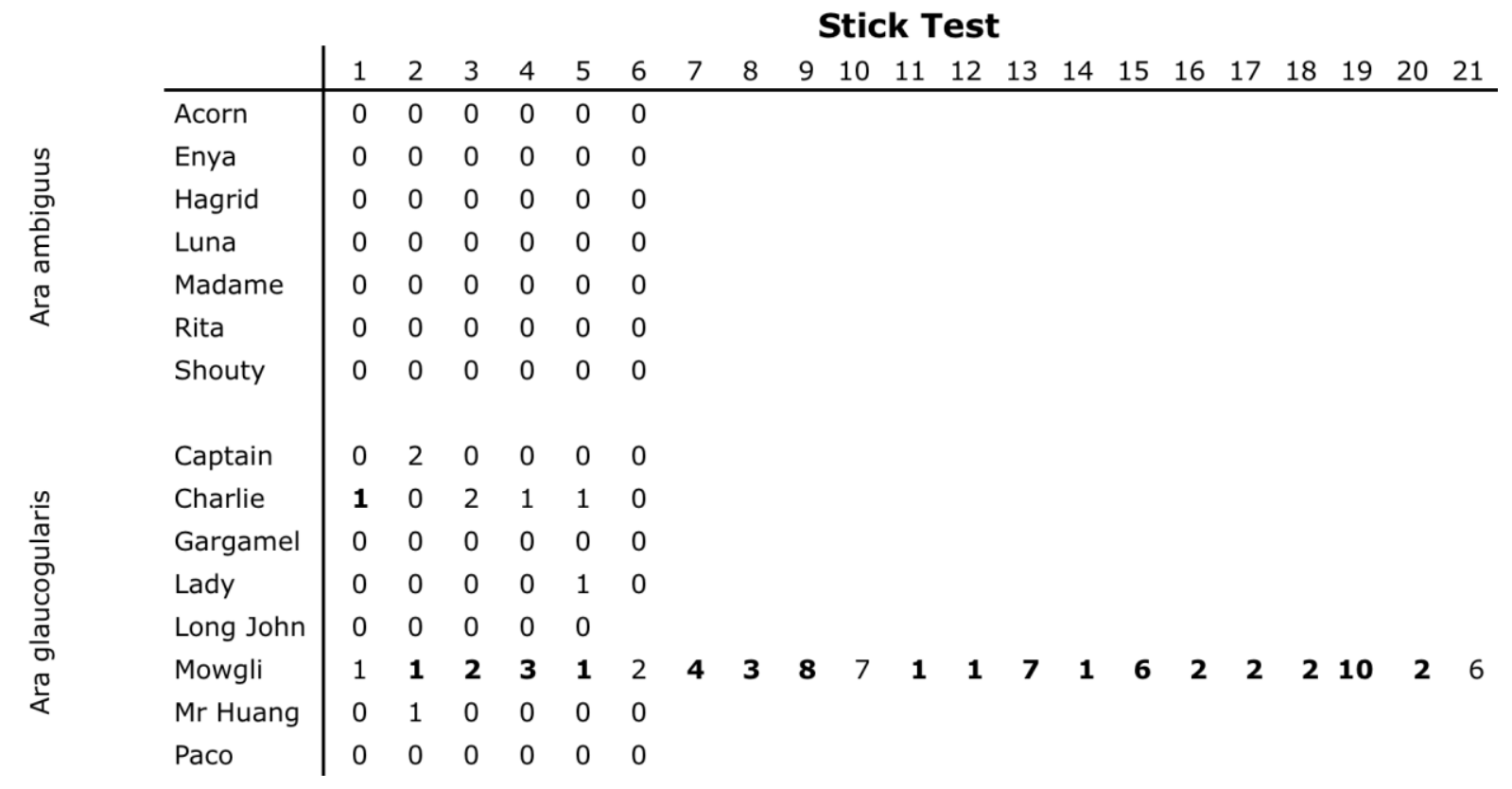

839 Table 3 The number of times subjects inserted the stick into the tube in the stick test transfer. Trials in which subjects succeeded to 840 make the platform collapse are in Bold. Mowgli did not reach the success criteria of ' 12 uninterrupted successful trials without a

841 failure inbetween', but we stopped as he was becoming less motivated to participate in the experiment. There was a video error in 842 Long johns sixth trial, hence it is not recorded here. 
bioRxiv preprint doi: https://doi.org/10.1101/2020.08.24.264390; this version posted August 24, 2020. The copyright holder for this preprint (which was not certified by peer review) is the author/funder, who has granted bioRxiv a license to display the preprint in perpetuity. It is made available under aCC-BY-NC-ND 4.0 International license. 